\title{
Alloy Development, Manufacturing and Design for Magnesium Applications
}

\author{
Alan A. Luo \\ Department of Materials Science \& Engineering \\ Department of Integrated Systems Engineering \\ The Ohio State University, Columbus, OH 43210, USA
}

Keywords: Magnesium alloys, alloy development, manufacturing, design, applications

\section{Extended Abstract}

Materials, manufacturing and design are critical pillars in lightweight structures. As the lightest structural metal, magnesium has emerged as a promising structural material for lightweight applications in automotive and other transportation industries. This talk presents examples of magnesium alloy development using phase equilibria calculations and experimental validation. This talk will also summarize the latest process innovations in magnesium manufacturing (casting, forming and joining) for structural applications. Process simulation and multi-scale microstructure modeling techniques are used to develop and optimize these manufacturing processes for automotive lightweighting. Engineering design is a system optimization and iteration process that combines material properties and manufacturing processes to meet product requirements at the lowest mass and/or cost. Future trends in multi-material applications and the integrated computational materials engineering (ICME) are also discussed.

Mg-Al-Sn alloy system offers good combination of strength, ductility, castability and corrosion resistance for potential structural applications. The solidification microstructure and mechanical properties of as-cast $\mathrm{Mg}-\mathrm{Al}-\mathrm{Sn}$ alloys have been investigated using computational thermodynamics and experiments. The as-cast microstructure of $\mathrm{Mg}-\mathrm{Al}-\mathrm{Sn}$ alloys consists of $\alpha-\mathrm{Mg}, \mathrm{Mg}_{17} \mathrm{Al}_{12}$ and $\mathrm{Mg}_{2} \mathrm{Sn}$ phases. The amount of $\mathrm{Mg}_{17} \mathrm{Al}_{12}$ and $\mathrm{Mg}_{2} \mathrm{Sn}$ phases formed increases with increasing $\mathrm{Al}$ and/or Sn content, and show good agreement between the experimental results and the Scheil solidification calculations. Generally, the yield strength of as-cast alloys increases with Al and/or Sn content, while the ductility decreases. Two experimental alloys, AT72 (Mg-7Al-2Sn) and AT96 (Mg-9Al$6 \mathrm{Sn}$ ), were designed and prepared using high pressure die casting process. The microstructure of as-cast $\mathrm{Mg}-\mathrm{Al}-\mathrm{Sn}$ alloys was investigated using computational thermodynamics modeling and experimental techniques. Both alloys show improved mechanical properties and excellent die castability compared with the conventional AZ91 (Mg-9Al-1Zn) and AM50 (Mg-5Al-0.3Mn) alloys.

This talk summarizes the melting and casting processes for magnesium alloys. It also reviews the historical development of magnesium castings and their structural uses in the western world since 1921 when Dow began producing magnesium pistons. Magnesium casting technology was well developed during and after World War II, both in gravity sand and permanent mold casting as well as high-pressure die casting, for aerospace, defense and automotive applications. In the last 20 years, most of the development has been focused on thin-wall die casting applications in the automotive industry, taking advantages of the excellent castability of modern magnesium alloys. Recently, the continued expansion of magnesium casting applications into automotive, defense, aerospace, electronics and power tools has led to the diversification of casting processes into vacuum die casting, low-pressure die casting, squeeze casting, lost foam casting, ablation casting as well as semi-solid casting. This talk will also review the historical, current and potential structural use of magnesium with a focus on automotive applications.

As magnesium is expanding into more critical structural applications, there is a great need for developing wrought magnesium products to provide improved mechanical and physical properties, crash performance and corrosion resistance. Most critical is to improve the plasticity of wrought magnesium, which becomes dramatically reduced as the various working methods used to create the primary fabrications, like sheet and extrusions, rotate the grains to less favorable orientations for isotropic plasticity. As a result, secondary forming processes like stamping and tube hydroforming need to be executed at warm temperatures to promote non-basal slip to occur so that the larger strains targeted can be accommodated. This need increases manufacturing costs and puts magnesium at a disadvantage compared with traditional metals. Further, since final performance occurs at ambient temperatures, the plasticity of magnesium at these temperatures remains paramount to their in structural applications. Finally, the high electrochemical activity of magnesium has limited its application due to concerns for galvanic corrosion. Mitigating solutions are either still not robust enough or too expensive for high volume manufacturing. Similar to magnesium plasticity, the use of magnesium for exterior exposed panels, requiring a high degree of finish for their appearance, remains an equally challenging situation.

Integrating magnesium into today's steel-dominated structures is challenging, and requires intelligent selection of materials and manufacturing processes for critical lightweight applications. The Mg-intensive front end body structures were selected by USAMP (United States Automotive Materials Partnership) to demonstrate the lightweight benefits of magnesium applications and the enabling technologies. The $\mathrm{Mg}$-intensive front end design achieved $44.57 \mathrm{~kg}(45 \%)$ mass saving compared with the steel baseline (unibody architecture), with equivalent stiffness, durability (fatigue) and crashworthiness predicted by simulations.

Integrated Computational Materials Engineering (ICME) is the integration of materials information, captured in computational tools, with engineering product performance analysis and manufacturing-process simulation. The development and application of ICME tools will accelerate the use of magnesium in lightweight structural applications. 